\title{
Home Health Aides: The Burgeoning Backbone of the Health Care System
}

\author{
Margo H. Schmiederer ${ }^{1}$ \\ ${ }^{1}$ School of Medicine, Case Western Reserve University, Cleveland, $\mathrm{OH}$ \\ Corresponding Author: Margo H. Schmiederer, 515 Curtin Drive, Morrisville, PA 19067, (267) 808-1418, mhs112@case.edu \\ Submitted June 4, 2021 Accepted November 8, 2021 Published January 28,2022 https://doi.org/10.18061/ojph.v4i2.8374
}

By 2030, the entirety of the baby boomer generation will have shifted into the ranks of older adulthood (65 years old and older), making up $20.3 \%$ of the United States population. Older adults utilize more health care services than younger groups as the majority of them have at least one chronic condition that requires care. ${ }^{1}$ The health care system is approaching a turning point: How will we care for our aging population?

Studies continuously show that keeping the elderly in their homes is the best option for improving health outcomes and lowering health care costs. It is also typically the desire of the patient. AARP estimates that nearly $90 \%$ of people over age 65 want to stay in their home for as long as possible. ${ }^{2}$ Home health aides (HHAs), workers who provide assistance to patients with activities of daily living in the home, allow patients to age safely in place. The demand for in-home care is expected to increase with a $33 \%$ rise in job prospects. ${ }^{3}$ With Ohio's elderly population growing 20 times faster than its general population, it is crucial that the health care system start taking the HHA occupation seriously.

I have been working as a part-time aide to a 90-year-old man for nearly a year. My tasks include helping him dress, preparing his medications, helping him get to and from his walker, and grocery shopping. My assistance is mostly companionship, conversation, and ensuring that his basic needs are met. I work as an HHA as a 'side-gig' because the wage is not sufficient to make a living with an average compensation of about $\$ 12.15$ per hour. ${ }^{4}$ Many of the HHAs that I work with are immigrants and work several jobs as well. We do not receive any benefits, nor do we have many opportunities for professional development.

The burgeoning issue is the lack of a home care workforce. The Ohio Department of Aging notes that workforce capacity is among "key issues facing Ohio's aging population" in its 2021 Annual Report. The Ohio Provider Resource Association similarly states that industry efforts to recruit HHAs in Ohio have proven futile, leaving the state "in crisis."5

An alternative option is caring for older adults in inpatient nursing care facilities, the cost of which are tremendous when compared to in-home services. The Ohio Association of Area Agencies on Aging estimates that inpatient facilities cost about $\$ 6361$ per month while in-home services cost around $\$ 1225$ per month. ${ }^{6}$ Additionally, emerging legislation in the state called Esther's Law highlights the issue of abuse and neglect in inpatient settings. ${ }^{7}$ In 2019, Ohio's nursing homes ranked among the nation's lowest in quality of care with $41 \%$ of the facilities earning a below-average Medicare rating. ${ }^{8}$

Luckily, under Governor Mike DeWine, the reimbursement rates to Medicaid for in-home and community-based health care services are set to increase beginning November 2021. This will impact the nearly 200000 Ohioans on the program by increasing in-home care opportunities for such individuals.

Home health aides provide some of the most essential work for society by caring for the elderly in their homes; in many ways they are the backbone of the health care system. It is long overdue that the profession receive investment in the form of wage and benefit increases via greater reimbursement rates, opportunities for professional development, and general acknowledgement of the profession's importance by the public health system. The increase in reimbursement rates is a small step in the direction of improving the in-home care options for our nation's elderly.

\section{REFERENCES}

1. Retooling for an Aging America: Building the Health Care Workforce. Institute of Medicine Committee on the Future Health Care Workforce for Older Americans. 2008. Accessed August 20, 2021. https://pubmed.ncbi.nlm.nih.gov/25009893/ 
2. Aging in Place: A State Survey of Livability Policies and Practices. AARP Public Policy Institute. 2011. Accessed August 20, 2021.

https://www.aarp.org/content/dam/aarp/livable-communities/oldlearn/research/aging-in-place-a-state-survey-of-livability-policies-and -practices-aarp.pdf

3. Home Health and Personal Care Aides: Job Outlook. U.S. Bureau of Lab Statistics. Updated September 8, 2021.

https://www.bls.gov/ooh/healthcare/home-health-aides-andpersonal-care-aides.htm

4. Ortman J, Velkoff V, and Hogan H. An Aging Nation: The Older Population in the United States. Population Estimates and Projections. Census Bureau. Published May 2014.

https://www.census.gov/library/publications/2014/demo/p251140.html

5. Gordon K. Home health care industry 'in crisis' leaves people scrambling to find help for loved ones. The Columbus Dispatch. Updated October 2, 2021. Accessed October 26, 2021.

6. Wu T. Historically underfunded, home and community-based care in Ohio finally will get $\$ 517$ million boost. The Columbus Dispatch. Published September 29, 2021. Accessed October 26, 2021.

https://www.dispatch.com/story/news/healthcare/2021/09/30/ home-care-ohio-see-fmap-arpa-medi caid-reimbursement-hcbswaivers-disability-covid-19/5833726001/

7. Wu T. Esther's Law, which would allow cameras in nursing home rooms, gains traction in Ohio. The Columbus Dispatch. Published October 11, 2021. Accessed October 26, 2021.

https://www.dispatch.com/story/news/politics/2021/10/12/abusecameras-ohio-nursing-home-roo ms-esthers-law-steve-piskor-assisted -living-reform-elderly/6004535001/

8. Caniglia J, Corrigan JE. Ohio nursing homes among the nation's lowest rated in quality of care: A Critical Choice. The Plain Dealer. Published January 11, 2019. Accessed October 26, 2021. https://www.cleveland.com/metro/2017/03/ ohio_nursing_homes_among_the_nations_lowest_rated_in_quality_of_ca re_a_critical_choice.html 